\title{
Insuring catastrophes and the role of governments
}

\author{
M. M. Boyer ${ }^{1}$ and C. M. Nyce $^{2}$ \\ ${ }^{1}$ HEC Montréal, Université de Montréal, 3000 chemin de la Côte-Ste-Catherine, Montréal, Québec, QC H3T 2A7, Canada \\ ${ }^{2}$ Florida Catastrophic Storm Risk Management Center, College of Business, Florida State University, Tallahassee, Florida, \\ FL 32306-1110, USA
}

Correspondence to: M. M. Boyer (martin.boyer@hec.ca) and C. M. Nyce (cnyce@cob.fsu.edu)

Received: 21 December 2012 - Published in Nat. Hazards Earth Syst. Sci. Discuss.: -

Revised: 27 March 2013 - Accepted: 15 April 2013 - Published: 16 August 2013

\begin{abstract}
In this paper we model the cost of providing insurance coverage against natural and man-made hazards. We propose an insurance market model that explains (1) the use of reinsurance to help finance the cost of catastrophic events and (2) the implicit (or explicit) presence of government entities acting as (re)insurers of last resort. Using an economic model, we show how insurance programmes should be designed to cover the losses due to a possible catastrophic natural hazard. Our results show that the optimal structure of a reinsurance programme minimizes the cost of offering insurance protection. We also show how government intervention can reduce the cost of insurance against natural catastrophes and increase policyholders' welfare. Our paper therefore offers public policy implications as to the role and presence of government as an insurer of last resort and the minimum insurance premium necessary to cover the cost of catastrophic events.
\end{abstract}

\section{Introduction}

\subsection{Motivation}

The insurance industry's capacity to absorb large, catastrophic losses is a concern not only for insurance providers, but also for consumers, regulators and, perhaps even more importantly, for public policymakers. Insurers operate efficiently when there are a large number of relatively small, uncorrelated individual risks to insure. When these risks are correlated, however, insurers have a more difficult time offering protection (see Borch, 1962). As a result, their cost of capital can become so expensive that insurance is no longer economically sound (see Cummins and Trainar, 2009). Rein- surance contracts - that is, insurance protection for insurers have traditionally been used to share catastrophic risk within the insurance industry. Lately, however, the cost of large natural hazards has become so large that alternative capital market products, such as cat bonds, have become increasingly popular to offset very high losses (see Cummins et al., 2002; Albertini and Barrieu, 2009). That being said, reinsurance (i.e. insurance for insurers) remains the main risk-sharing vehicle used by insurers to transfer the cost of catastrophic risk.

Motivation for this paper stems not only from the magnitude and uncertainty regarding potential natural hazard losses, but also from the public policy discussions of the best methods of financing losses associated with these risks. The optimal methods of catastrophe risk financing will delineate the respective roles of the private insurance market, reinsurers, capital markets, and government entities - irrespective of their ability to properly evaluate natural hazards (see Plattner, 2005; Plattner et al., 2006). With the discussions in the United States and in Europe of national or multistate catastrophe pools to spread the cost of natural hazards, the roles of insurers, reinsurers and public entities increasingly become a public policy issue. A more exhaustive study of the optimality of insurance and reinsurance programmes can aid public policymakers in making decisions in the best interests of their constituents. As meteorologists, oceanographers, wind and structural engineers, and other earth and wind scientists work toward developing more accurate estimates of expected losses, actuaries, economists, and financial engineers need to work toward developing better and more efficient methods of financing these potential losses.

Worldwide, the costs and damage associated with catastrophic events continue to increase (Kunreuther and MichelKerjan, 2009). These events can be natural (earthquake, 
flood, windstorm, etc.) or man-made (terrorism, oil spill, chemical spills) as in Borst et al. (2006), or a combination of both as in Kraussman et al. (2011). The one source of damage garnering the most interest from the insurance industry is windstorm. For example, more than $45 \%$ of total catastrophe losses in the United States since the 1990s are due to hurricanes and tropical storms (see Michaelides et al., 2011, and the references therein for the case of Mediterranean storms). The population growth and property development in windprone coastal areas have greatly increased the value of property exposed to such events. For instance, hurricane-prone American states have more than USD 4 trillion in aggregate coastal exposure (AIR Worldwide, 2008); this is roughly the equivalent of Germany's gross domestic product.

Significant uncertainty regarding the magnitude of future losses exists (Kunreuther and Michel-Kerjan, 2009). Global warming would indicate higher sea surface temperatures, which in turn would indicate an increase in both the frequency and severity of storms (Emanuel, 2007). Additional research, however, has found no impact on the total frequency of storms, but has shown an increase in the frequency of the most severe storms (Elsner et al., 2008).

Financing of catastrophic risk is increasingly becoming a public policy issue for governments (see Kessler, 2008, for more details on the economic foundations of the role of the state as an insurer of last resort). The growth of governmentrun residual markets in hazard-prone areas in the United States (see Hartwig and Wilkerson, 2007, 2010, 2012) increases the importance of finding the proper role and price for private market insurance. Our paper seeks to answer the following two questions regarding the market for catastrophe and natural hazards insurance:

1. How should an insurance-cum-reinsurance programme be designed?

2. Should government entities be involved in catastrophic risk financing, and if so, at what level?

\subsection{A (short) primer on insurance and reinsurance}

Property insurance products are generally designed to indemnify the property owner in case of loss. One can separate the inputs needed in the production of these insurance products into two components: labour and capital. Labour is needed for insurers as the provider of two types of expertise: underwriting (that is, the ability to assess and measure risk properly) and claims adjusting (to make sure that insurance indemnity payments are made to the right party at the right time for the right reason and in the right amount). Capital is needed to support the insurers' payment promises, to secure the insurers' ability to pool individual risks and to reduce their risk of insolvency. Although insurers and reinsurers share common characteristics, the distinctions between these two services are especially relevant to the provision of catastrophe insurance.
The cost of capital and the ability to underwrite and adjust claims at the individual risk level are critical factors in determining where in the loss distribution insurers and reinsurers would be most efficient in providing coverage. As argued by Kleffner and Doherty (1996) and de Lourdes Centeno and Simoes (2009), reinsurers often have better diversification opportunities than primary insurers if only because they do not face the same regulatory oversight as primary insurers.

Reinsurers do not have the same underwriting and claims adjusting ability that primary insurers have. Primary insurers therefore offer these services at a lower marginal cost than reinsurers. When transaction costs are relatively low, the use of a reinsurance contract with proper attachment points combines the primary insurers' underwriting and claims adjusting services with the reinsurers' ability to obtain capital at low cost.

Finally, we can very well imagine that because of their taxing authority, governments have the highest ability to access the capital markets and the lowest cost of bearing risk. We can also easily assume that governments have the worst underwriting ability because they are not in the business of selling insurance (see Lewis and Murdock, 1996).

\subsection{Public policy and insurance}

As public policymakers are increasingly aware of the impact of insurance affordability of their constituents, government intervention in insurance markets has increased in hazardprone areas. Over the past decade, local governments have acted as insurers, and federal (or central) governments have stepped in to compensate financially areas hit the hardest by natural catastrophes. Another mechanism used to increase affordability is to limit the financial responsibility of primary insurers through a public reinsurance mechanism.

As noted in Hartwig and Wilkinson (2012), the United States has more than 3.3 million policyholders in residual property insurance markets (i.e. markets that are under the direct responsibility of state governments) and more than USD 884 billion in exposure to loss (both in 2011). While the policy count in property markets has increased three-fold since 1990, the exposure has grown fifteen-fold. This does not include other state and federal property insurance programmes in the US including the California Earthquake Authority, the National Flood Insurance Program, or the Federal Terrorism Insurance Program. The most pronounced example of changes in government intervention into property insurance in the United States is Citizens Property Insurance Corporation, which is a combination of the windstorm pool and Fair Access to Insurance Requirements (i.e. FAIR plans) in Florida. Designed as the property insurer of last resort ${ }^{1}$, Citizens had more than 1.2 million policyholders at the end

\footnotetext{
${ }^{1}$ See Cole et al. (2011) for a more complete discussion of the expansion of Citizens and the inherent subsidies created.
} 
of 2011 and more than $20 \%$ of the market share in the state of Florida.

Assuming such interventions can be welfare enhancing, they should be designed to be the most efficient. We will thus look at catastrophe and natural hazard insurance contracts and programmes from the point of view of a public policymaker who seeks to structure the insurance/reinsurance market to minimize the total cost of purchasing insurance against a catastrophic loss.

\section{Modelling strategy}

Boyer and Dupont-Courtade (2013) show that reinsurance programmes are mostly structured in layers (see also Hurlimann, 2003; Ladoucette and Teugels, 2006) - see Fig. 10 for an example of a reinsurance programme. Insurance economists (Powell and Sommer, 2007; Berger et al., 1992; Garven and Lamm-Tennant, 2003) have seen the purchase of reinsurance as a capital structure decision, with equity capital and reinsurance acting as substitutes. Insurers that have a suboptimal amount of reinsurance will therefore have lower operating efficiency, which means that reinsurance becomes an important component of insurer efficiency. It can also be an important lever of public intervention.

The model we develop assumes that all policyholders are trying to minimize the premium paid (total cost of their insurance contract). This cost includes the expected economic loss (in insurance terms, the pure premium) which is exogenously determined and must be borne by someone in the economy, as well as the insurer's labour expenses (the underwriting and claims administrative costs, including loss adjustment expenses) and its capital cost of bearing the risk. As we shall show, it is the relationship between labour and capital that dictates what is the optimal insurance/reinsurance contract structure. We will therefore posit that the total premium of the insurance contract is a zero-profit contract, given by $\Pi=E[Y]+C(Y)$, where $E[Y]$ is the expected loss (i.e. the aforementioned pure premium) and $C(Y)$ is the total cost of the insurance services that includes labour and capital costs. We will assume in our model that the policyholders' goal is to minimize the premium (total cost of their insurance programme). As shown in the model, this can be done by minimizing the total cost of the insurance services, $C(Y)$.

The loss $Y$ is distributed according to some density function $g(Y)$ over the range $Y \in[0, \hat{Y}]$, where $\hat{Y}$ is the maximum possible loss. We can therefore write the expected loss as

$$
E[Y]=\int_{0}^{\hat{Y}} Y g(Y) \mathrm{d} Y .
$$

The question now becomes one of modelling the labour and capital cost of insurance services, $C(Y)$.
The model we propose assumes that there are $N$ potential entities that could sell insurance protection in a competitive market. These entities could be private (re)insurers, governments, or quasi-governmental programmes. The marginal cost function we use depends on the insurer's cost of capital (which we shall denote $k$ ) and its underwriting and claimshandling ability (which we shall denote $b$ ). For any of these entities, $n$, we shall assume that the marginal cost associated with a possible loss of magnitude $Y$ is a linear ${ }^{2}$ function (see Froot and O'Connell, 2008; Ibragimov and Walden, 2007; Ibragimov et al., 2009) with two parameters, given by Eq. (1), where $\hat{Y}$ is the maximum possible loss $(Y \in[0, \hat{Y}])$, and entities in the economy differ with respect to their $b_{n}$ 's and $k_{n}$ 's:

$C_{n}^{\mid}(Y)=b_{n}+k_{n} Y$.

The logic behind this linear marginal cost of providing insurance services is anchored in the principle that information becomes more costly to obtain when the insuring entity becomes more removed from the risk that is insured (see Fazzari et al., 1988; Jean-Baptiste and Santomero, 2000). Also, Zanjani (2002) argues that since reinsurers are significantly exposed to capital outflows when a catastrophe hits, the cost of providing capital for very large catastrophes increases by more than the expected liability amount. In other words, the marginal price of insurance should be an increasing function of the marginal liability.

The policyholder's goal is to find the policy that minimizes the premium (total cost of insuring against a possible loss $\hat{Y}$ ). In other words, policyholders choose an insurance contract, or a set of insurance contracts, that minimizes the integral of the marginal cost function plus the expected loss:

$\Pi=E[Y]+C(Y)=\int_{0}^{\hat{Y}} Y g(Y) \mathrm{d} Y+\int_{0}^{\hat{Y}} C_{n}^{\dagger}(Y) \mathrm{d} Y$.

As we assume that the expected loss is independent of the structure of the insurance and reinsurance programme, the problem reduces to one of minimizing the area under the marginal cost function.

\subsection{Single insurance provider}

If there is only one type of entity in the economy that sells insurance (with $b_{n}=b$ and $k_{n}=k$ ), then there is no "choice" of the insurance programme structure as the lowest possible premium is obtained when

$C(\hat{y})=\int_{0}^{\hat{y}}[b+k y] \mathrm{d} y=\left[b y+\frac{1}{2} k y^{2}\right]_{0}^{\hat{y}}=\left[b \hat{y}+\frac{1}{2} k \hat{y}^{2}\right]$.

Figure 1 illustrates the situation.

\footnotetext{
${ }^{2}$ The marginal cost does not need to be a linear function of the maximum possible loss; the main results of the paper will also hold
} 


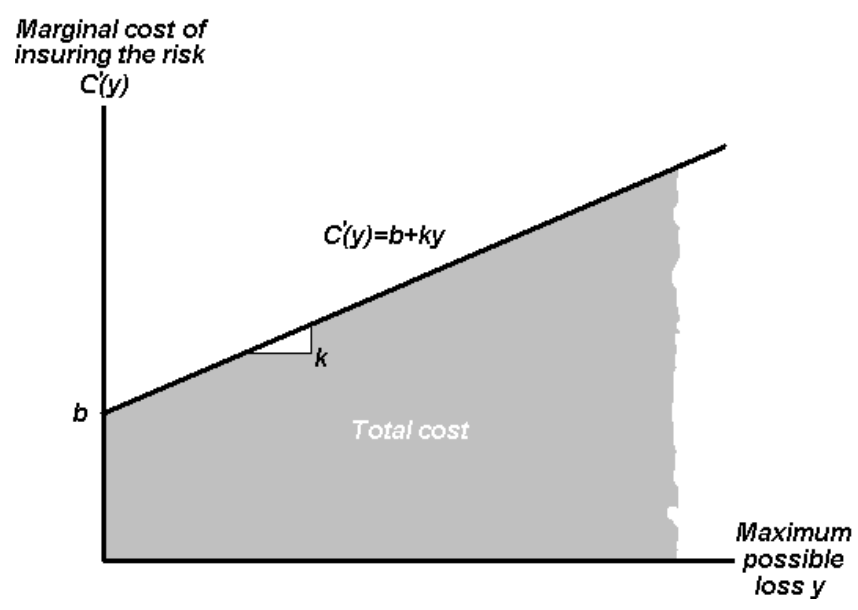

Fig. 1. Cost-minimizing contract with 1 entity.

Since there is only one insurer and no reinsurer, there is no attachment point choice as there is no second layer. The premium paid by the policyholders is then given by the total cost of bearing the maximum possible loss $\hat{Y}$ (i.e. the area under the marginal cost function) plus the pure premium.

\subsection{Two insurance providers}

Now suppose there are two entities $n_{1}$ and $n_{2}$ such that $b_{1}<b_{2}$ and $k_{1}>k_{2}$. This means that the intercept of entity $n_{1}$ 's marginal cost is lower than entity $n_{2}$ 's. Put differently, $n_{1}$ is able to provide underwriting and claims service marginally cheaper than $n_{2}$. However, each dollar of coverage (marginal cost of capital) is more expensive for entity $n_{1}$. The question becomes how to combine the two entities' technology to minimize the total premium (cost of the risk) to the policyholder. Because one entity has a lower intercept but a higher slope, a policyholder will minimize the total cost by dealing with the low-intercept entity (better underwriting and claims service) for lower losses and the lowslope entity (lower marginal cost of capital) for higher losses. Graphically (see Fig. 2), we see that the total cost of bearing risk of potential loss $\hat{Y}$ is a combination of the two entities: the low-intercept entity is responsible for losses up until point $y_{1}$ and the low-slope entity is responsible after point $y_{1}$.

Changing vocabulary to fit with the insurance industry's we can say that entity $n_{1}$ is the primary insurer, whereas entity $n_{2}$ is the reinsurer that assumes losses greater than $y_{1}$. The question becomes: at what point should the reinsurer become liable? Put differently, where should $y_{1}$ be to minimize the total cost of bearing this risk? Abstracting from the expected loss component of the total premium, which we assume to be exogenously given, social welfare is maximized by minimizing the total cost of providing insurance services to policyholders. This is the equivalent of the fol-

if the marginal cost is an increasing non-concave function of the maximum possible loss.

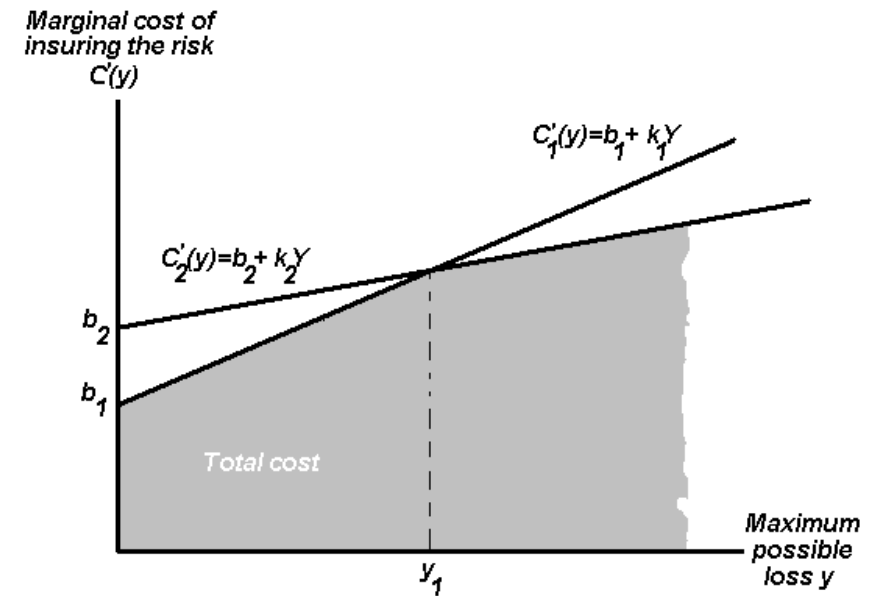

Fig. 2. Cost-minimizing contract with 2 entities.

lowing minimization problem:

$\operatorname{Min}_{y_{1}} \int_{0}^{y_{1}}\left[b_{1}+k_{1} y\right] \mathrm{d} y+\int_{y_{1}}^{\hat{y}}\left[b_{2}+k_{2} y\right] \mathrm{d} y$.

Solving this minimization problem ${ }^{3}$ gives us $y_{1}^{*}=\frac{b_{2}-b_{1}}{k_{1}-k_{2}}$, so that we have that the primary insurer is responsible for the first $y_{1}^{*}$ dollars and the reinsurer is responsible for the last $\hat{y}-y_{1}^{*}$ dollars.

\section{3 $\quad N$ insurance providers}

Now suppose there are $N$ entities such that $b_{1}<b_{2}<\ldots<$ $b_{N}$ and $k_{1}>k_{2}>\ldots>k_{N}$. This means that entity $n_{1}$ 's marginal cost intercept is lower than entity $n_{2}$ 's, which is lower than $n_{3}$ 's, etc. Each dollar of coverage (marginal cost of capital) is more expensive for entity $n_{1}$ than for $n_{2}$ than for $n_{3}$, etc. As before, the optimal combination of the $N$ entities' technology will be for the policyholder to deal with the entity that has the lowest intercept first (it has the best underwriting and claims service technology), and then ask that reinsurance steps in at different layers when having a low marginal cost of capital becomes important. Layers are determined by the comparative advantage of each reinsurer at assuming catastrophic losses.

$$
\begin{gathered}
3 \\
\operatorname{Min}_{y_{1}}\left\{\left[b_{1} y+\frac{1}{2} k_{1} y^{2}\right]_{0}^{y_{1}}+\left[b_{2} y+\frac{1}{2} k_{2} y^{2}\right]_{y_{1}}^{\hat{y}}\right\} \\
=\operatorname{Min}_{y_{1}}\left\{\left(b_{1}-b_{2}\right) y_{1}+\frac{1}{2}\left(k_{1}-k_{2}\right) y_{1}^{2}\right\}
\end{gathered}
$$


As the market allows more and more insurers that have different underwriting expertise $(b)$ and risk-bearing capacities $(k)$, the total cost to policyholders, excluding the pure premium, is decreased. If there are $N$ private insurers and reinsurers such that $b_{1}<b_{2}<\ldots<b_{N}$ and $k_{1}>k_{2}>\ldots>k_{N}$, the cost minimization problem writes

$$
\underset{y_{1}, \ldots, y_{N}}{\operatorname{Min}}\left\{\int_{0}^{y_{1}}\left[b_{1}+k_{1} y\right] \mathrm{d} y+\sum_{i=2}^{N} \int_{y_{i-1}}^{y_{i}}\left[b_{i}+k_{i} y\right] \mathrm{d} y\right\} .
$$

Reinsurance in this economy "concavifies" the overall marginal cost function as can be seen in Fig. 3. By increasing the number of entities (i.e. reinsurers) one increases the concavity of the marginal cost function and therefore reduces total cost. The solution is clearly then to have

$y_{i}^{*}=\frac{b_{i+1}-b_{i}}{k_{i}-k_{i+1}} \quad$ for all $\quad i \in 1, \ldots N-1$.

\section{A market equilibrium}

Clearly the equilibrium on this market will depend on how the parameter values $b_{i}$ and $k_{i}$ of all private insurers and reinsurers are distributed in the economy. Suppose there are two insurers, insurer $h$ with $b_{h}$ and $k_{h}$, and insurer $j$ with $b_{j}$ and $k_{j}$. If $b_{h}<b_{j}$ and $k_{h}<k_{j}$, then cost minimization will be obtained by having only one insurer. In other words, insurer $h$ here dominates insurer $j$ for whatever level of loss: it has better underwriting expertise and a lower cost of bearing risk. In an efficient market, insurer $j$ would find itself filing for bankruptcy.

Suppose now that $b_{h}<b_{j}$ and $k_{h}=k_{j}$ so that both insurers have the same risk-bearing technology, but one insurer (insurer $h$ ) has better underwriting expertise than the other. In other words, one insurer can do the same underwriting job, but at a lower cost. Again, insurer $j$ would find itself filing for bankruptcy since it has a more costly production function that insurer $h$. A similar story can be told if $b_{h}=b_{j}$ and $k_{h}<k_{j}$, so that both insurers have the same underwriting ability but one insurer (insurer $h$ ) has a better ability to assume large losses than the other insurer in the sense that insurer $h$ 's cost of assuming the risk is lower. Clearly insurer $j$ would find itself filing for bankruptcy, again, since it has a more costly production function that insurer $h$.

For a reinsurance market to exist in equilibrium, it therefore has to be that the reinsurers' marginal cost functions have a higher intercept and a lower slope. If this is not the case, then the entire potential loss of a policyholder will be assumed by a single unique insurer. In reality, we know that primary insurers rely on reinsurers to guarantee eventual indemnity payments for the highest levels of potential losses. Consequently, in the absence of market imperfections a policyholder's loss will be handled by more than one entity only

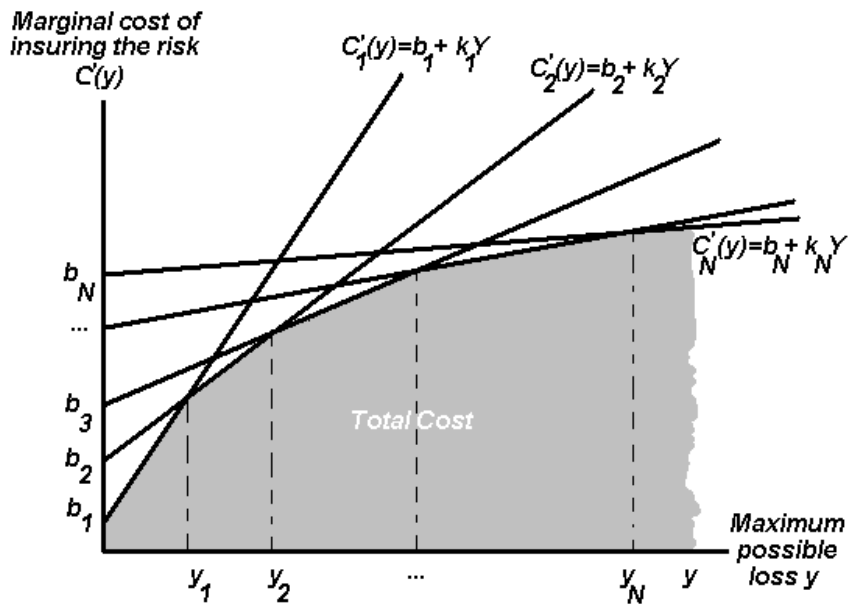

Fig. 3. Cost-minimizing contract with $N$ entities.

if reinsurers have a lower cost of bearing large risks than primary insurers.

By adding more insurance entities that have different $b$ 's and $k$ 's generates a market equilibrium where primary insurers are those that have the lowest $b$ 's and reinsurer involvement through excess-of-loss contracts depends on the right combination of $b$ 's and $k$ 's, with the reinsurer with the lowest $k$ and the highest $b$ assuming the highest tranche. If two or more entities have the same $b$ and the same $k$, then they split equally the tranche in which they belong in the marginal cost hierarchy. The working layer in Fig. 10 shows this relationship in an insurance programme chart.

\section{The (potential) role of government as an insurance provider}

\subsection{Public policy implications of government intervention}

In this model, governments can become insurance entities. We are assuming that a government entity has the lowest cost of raising capital through its ability to tax (so it has the lowest marginal cost of bearing risk, $k_{\mathrm{g}}$ ) but that it has the highest underwriting cost since it has no expertise in the matter (so it has the highest intercept, $\left.b_{\mathrm{g}}\right)^{4}$. And because the government

\footnotetext{
${ }^{4}$ While government debt is generally cheaper than private market sources of capital, the shadow value of the taxes necessary for the debt service may not be cheap. The overall government "cost" of financing catastrophic risk will vary with the government's budget situation as well as the magnitude of the potential losses. The possibility exists that some smaller, more leveraged governments may have a higher cost of capital than a large multinational (re)insurer. Violations of the assumption that governments have the lowest cost of capital would result in some countries where the government should not be providing insurance. Similarly, it may be possible that some governments have the ability to efficiently underwrite and
} 
has the lowest $k$, it is natural that it would enter the insurance market as the reinsurer of last resort (see Kessler, 2008, for other reasons). Expanding the two-provider model with the third entity being a government insurance provider, the problem becomes a two-variable cost minimization problem as shown in Eq. (2). The solution, which is graphically displayed in Fig. 4, is such that $y_{1}^{*}=\frac{b_{2}-b_{1}}{k_{1}-k_{2}}$ and $y_{2}^{*}=\frac{b_{\mathrm{g}}-b_{2}}{k_{2}-k_{\mathrm{g}}}$.

$\operatorname{Min}_{y_{1}, y_{2}} \int_{0}^{y_{1}}\left[b_{1}+k_{1} y\right] \mathrm{d} y+\int_{y_{1}}^{y_{2}}\left[b_{2}+k_{2} y\right] \mathrm{d} y+\int_{y_{2}}^{\hat{y}}\left[b_{\mathrm{g}}+k_{\mathrm{g}} y\right] \mathrm{d} y$.

If reinsurance is not allowed, but government is still there as a reinsurer of last resort, the total cost would be higher by an amount that is represented in the graph by the yellow triangle. The government's marginal contribution to the reduction in total cost can also be measured as the lined area in red on the graph. Without the government as a reinsurer of last resort, private reinsurers would have to assume the risk from attachment point $y_{1}$ until the maximum possible loss $\hat{y}$. Thus, the total cost of insuring the loss would be greater by an amount that is represented by the lined red triangle. If there are $N$ private insurers and reinsurers such that $b_{1}<b_{2}<\ldots<b_{N}$ and $k_{1}>k_{2}>\ldots>k_{N}$, and a government whose parameters are $b_{\mathrm{g}}$ and $k_{\mathrm{g}}$ such that $b_{N}<b_{\mathrm{g}}$ and $k_{N}>k_{\mathrm{g}}$, which acts as a reinsurer of last resort, then the cost minimization problem becomes Eq. (3):

$$
\begin{aligned}
\operatorname{Min}_{y_{1}, \ldots y_{N}} & \left\{\int_{0}^{y_{1}}\left[b_{1}+k_{1} y\right] \mathrm{d} y+\sum_{i=2}^{N} \int_{y_{i-1}}^{y_{i}}\left[b_{i}+k_{i} y\right] \mathrm{d} y\right. \\
& \left.+\int_{y_{N}}^{\hat{Y}}\left[b_{\mathrm{g}}+k_{\mathrm{g}} y\right] \mathrm{d} y\right\} .
\end{aligned}
$$

Government intervention is not free. The premium governments should charge to the insurance market is given by

$\Pi_{\mathrm{g}}=\int_{y_{N}}^{\hat{y}} Y g(Y) d Y+\int_{y_{N}}^{\hat{y}}\left[b_{\mathrm{g}}+k_{\mathrm{g}} y\right] \mathrm{d} y$.

The benefit to policyholders is given by Eq. (4):

$\Gamma_{\mathrm{G}}=$

$$
\begin{aligned}
& \left(\int_{0}^{y_{1}}\left[b_{1}+k_{1} y\right] \mathrm{d} y+\sum_{i=2}^{N} \int_{y_{i-1}}^{y_{i}}\left[b_{i}+k_{i} y\right] \mathrm{d} y+\int_{y_{N}}^{\hat{y}}\left[b_{\mathrm{g}}+k_{\mathrm{g}} y\right] \mathrm{d} y\right) \\
& -\left(\int_{0}^{y_{1}}\left[b_{1}+k_{1} y\right] \mathrm{d} y+\sum_{i=2}^{N} \int_{y_{i-1}}^{y_{i}}\left[b_{i}+k_{i} y\right] \mathrm{d} y\right) .
\end{aligned}
$$

apply proper price discrimination among its citizens. Frequently opening the underwriting process to political interference does not result in efficient underwriting.

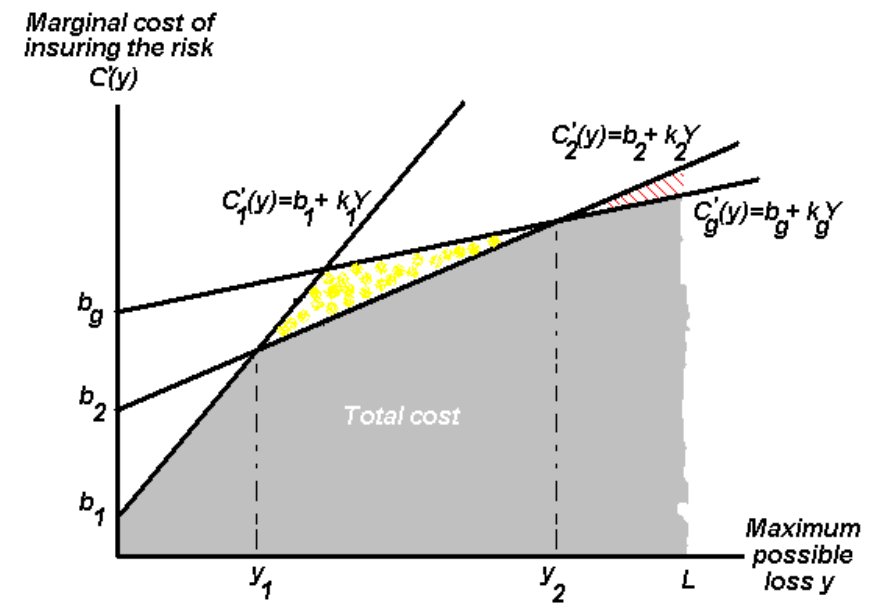

Fig. 4. Government entity as insurer.

More concisely, the benefit to government intervention is

$\Gamma_{\mathrm{G}}=\int_{y_{N}}^{\hat{y}}\left[\left(b_{N}-b_{\mathrm{G}}\right)+\left(k_{N}-k_{\mathrm{G}}\right) y\right] d y$,

which becomes

$\Gamma_{\mathrm{G}}=\left[\left(b_{N}-b_{\mathrm{G}}\right)\left(\hat{y}-y_{n}\right)+\frac{1}{2}\left(k_{N}-k_{\mathrm{G}}\right)\left(\hat{y}^{2}-y_{n}^{2}\right)\right]$

when we solve the problem explicitly.

\subsection{Public policy implications when agents have heterogeneous cost functions}

The question in terms of public policy will be to assess the parameter values $b_{i}$ and $k_{i}$ of all private insurers and reinsurers, as well as the government's, so that the government's optimal attachment point can be determined. With this type of model, where competition in the primary layer and working layers of reinsurance are dominated by firms with better underwriting and claims adjusting capabilities, there are no advantages to having a government entity provide insurance coverage. It is also possible that there is no point for government to become involved in the insurance market as a reinsurance of last resort if, for instance, we find that cost minimization is obtained in the private market because the solution would demand that $y_{N}=\hat{Y}$. As the maximum possible loss increases, however, it becomes more likely that a government entity is needed in the market as its lower cost of capital begins to outweigh its inability to underwrite and manage claims.

The public policy implications of having different levels of government involved in the supply of insurance are not trivial since such public intervention will affect the price of insurance and the wellbeing of insurers and policyholders. It will also have an impact on the tax base as every individual 
in the country becomes an "investor" of the government-asreinsurer. With the discussions in the United States and in Europe of multi-state catastrophe pools or a federal catastrophe pool, the roles of insurers, reinsurers and public entities increasingly becomes a public policy issue. A more exhaustive study of the optimality of attachment and detachment points can aid public policymakers in reaching better decisions.

The question of government intervention cannot be studied independently of the distribution of risk in the economy. In the model so far, all individuals face the same risk, which means that government intervention has no ex ante redistribution impact. As a result, provided that at some level the government's cost of capital is lower than the reinsurers' lowest, government intervention increases welfare. Suppose now that agents in the economy are heterogeneous with respect to the cost of providing them with insurance. Put differently, suppose that there is a proportion $\mu_{\theta}$ of agents (with $\sum_{\theta} \mu_{\theta}=1$ ) whose total cost of insurance services is given by $C^{\theta}(Y)$. All agents still face the same expected loss, but some are more costly to insure.

Using the case of one primary insurer, one reinsurer and government (whose cost of capital is independent of the private market's cost function), and letting the superscript represent the agents' "cost type" and subscript g refer to the government's technology, the problem (as shown in Fig. 5) becomes

$\operatorname{Min}_{y_{1}^{\theta}, y_{\mathrm{g}}^{\theta}} \int_{0}^{y_{1}^{\theta}}\left[b_{1}^{\theta}+k_{1}^{\theta} y\right] \mathrm{d} y+\int_{y_{1}^{\theta}}^{y_{\mathrm{g}}^{\theta}}\left[b_{2}^{\theta}+k_{2}^{\theta} y\right] \mathrm{d} y+\int_{y_{\mathrm{g}}^{\theta}}^{\hat{Y}}\left[b_{\mathrm{g}}^{\theta}+k_{\mathrm{g}} y\right] \mathrm{d} y$.

The optimal contract that minimizes the total cost of insurance will differ from one agent type to the next as the attachment and detachment points will not be the same for every contract. If the government was able to offer different protection (different attachment points) to different agent types, the allocation of total cost in the economy would be better for all as each agent would end up paying a total cost that is specific to him.

In reality governments rarely treat different agents differently. Instead, governments often use a one-size-fits-all approach in their policies (which may reflect their inability to underwrite or discriminate properly across types). Since most government-sponsored property casualty insurance programmes involve some subsidization of high risk exposures, there are also redistributive questions that need to be addressed. In Florida (see Nyce and Maroney, 2011), inland homeowners subsidize homeowners who live on the coast, and even properties slightly inland in the coastal area are subsidizing properties that are directly on the ocean.

There are two types of government involvement that would induce redistribution problems. In the first intervention, we will assume that government intervenes at the same level of loss for all agent types (that is, the government's attachment

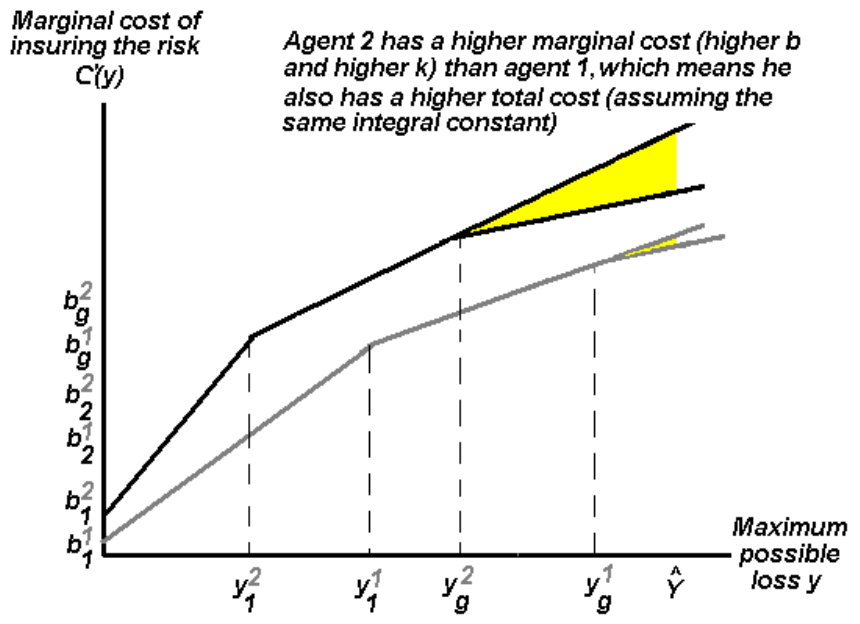

Fig. 5. Gain from government intervention.

point is the same for all). In the second, we will assume that government charges the same marginal cost to all the agents. In other words, parameters $b_{\mathrm{g}}$ and $k_{\mathrm{g}}$ are set by the government to be the same for all agents, and are therefore independent of $\theta$.

\subsubsection{Same government protection (i.e. same attachment point)}

In the model, the government's inability to discriminate results in every agent facing a government attachment point of $\hat{y}_{\mathrm{g}}$ determined exogenously. Each agent type's problem can then be written as

$\operatorname{Min}_{y_{1}^{\theta}} \int_{0}^{y_{1}^{\theta}}\left[b_{1}^{\theta}+k_{1}^{\theta} y\right] \mathrm{d} y+\int_{y_{1}^{\theta}}^{\hat{y}_{\mathrm{g}}}\left[b_{2}^{\theta}+k_{2}^{\theta} y\right] \mathrm{d} y+\int_{\hat{y}_{\mathrm{g}}}^{\hat{Y}}\left[b_{\mathrm{g}}^{\theta}+k_{\mathrm{g}} y\right] \mathrm{d} y$.

In this case, the government fixes the upper attachment point $\hat{y}_{\mathrm{g}}$ so that it is no longer a choice variable in the problem, as in Fig. 6.

If the government fixes its attachment point $\hat{y}_{\mathrm{g}}$ between the optimal attachment points of each type of agent, it is then easy to show that every agent ends up paying more for insurance services. To see why, observe the red wedges in Fig. 6 that represent the extra cost imposed on each agent by having a fixed attachment point; the yellow represents the gain to each agent for having government intervention.

As we see, the government's attachment point $\hat{y}_{\mathrm{g}}$ lies between the two type-specific (and optimal) attachment points $y_{\mathrm{g}}^{2}$ and $y_{\mathrm{g}}^{1}$. This means that, compared to the optimal typespecific entry point, government intervenes too early for the agents that have the lowest marginal cost (agent type $\theta=1$ ) and too late for the agents that have the higher marginal cost function (agent type $\theta=2$ ). As a result, both types of agents end up with a suboptimal situation. The loss of welfare for policyholders is then given by the sum of the two 


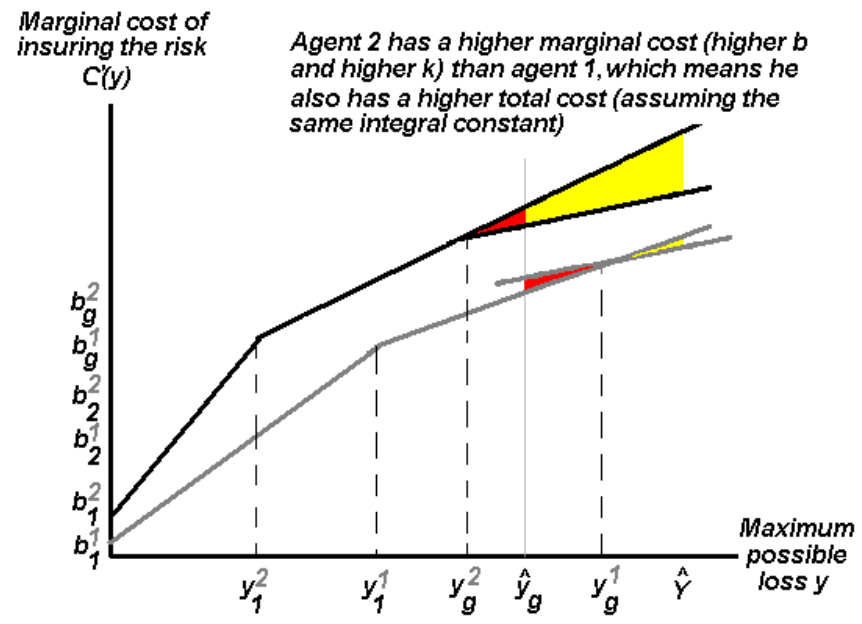

Fig. 6. Gain and loss from government intervention.

areas highlighted in $\mathrm{red}^{5}$. Interestingly, no government intervention that fixes its entry point can be optimal. To see why, suppose that $\hat{y}_{\mathrm{g}}<y_{\mathrm{g}}^{2}$. The situation would then look like that of Fig. 7.

As we can see, neither agent benefits from the government stepping in too early in the catastrophe risk market. In fact, whatever entry point government fixes, agents can never be better off if that entry point is the same for all and if agents differ with respect to their marginal cost function.

\subsubsection{Same marginal cost of government insurance}

The second type of redistribution the government can do is to forgo its ability to charge agents as a function of their marginal cost type. Instead the government may use an "average" cost for all. Given the way we have modelled the problem here, this means that the government's inability to discriminate results in every agent facing a government average "underwriting expertise cost" of $\hat{b}_{\mathrm{g}}=\sum_{\theta} \mu_{\theta} b_{\mathrm{g}}^{\theta}$. The problem for each agent type, which is illustrated in Fig. 8, then becomes like that in Eq. (6):

$\operatorname{Min}_{y_{1}^{\theta}, y_{2}^{\theta}} \int_{0}^{y_{1}^{\theta}}\left[b_{1}^{\theta}+k_{1}^{\theta} y\right] \mathrm{d} y+\int_{y_{1}^{\theta}}^{y_{2}^{\theta}}\left[b_{2}^{\theta}+k_{2}^{\theta} y\right] \mathrm{d} y+\int_{y_{2}^{\theta}}^{\hat{Y}}\left[\hat{b}_{\mathrm{g}}+k_{\mathrm{g}} y\right] \mathrm{d} y$.

By using the same intercept for all agents, the government's attachment point for the high-cost agents (agent type 2) decreases, but is increased for the low-cost agents (agent type 1). By doing so the high-cost agents are benefiting from the intervention, to the detriment of the low-cost agent. Each

\footnotetext{
${ }^{5}$ The losses in the red triangles can be calculated similar to the gains from Eq. (4). The losses would be the difference between the government entering at the optimal point $y_{\mathrm{g}}^{2}\left(y_{\mathrm{g}}^{1}\right)$ and the suboptimal point $\hat{y}_{\mathrm{g}}$ for agent type $2(1)$, rather than the gains from entering at $y_{\mathrm{G}}$ instead of $Y_{N}$.
}

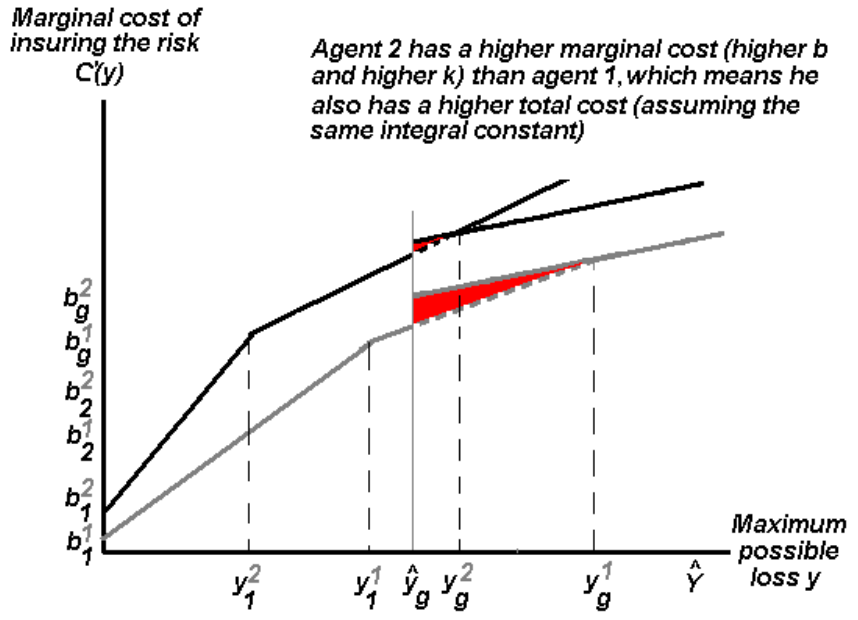

Fig. 7. Government intervention by fixing its attachment point below $y_{\mathrm{g}}^{2}$.

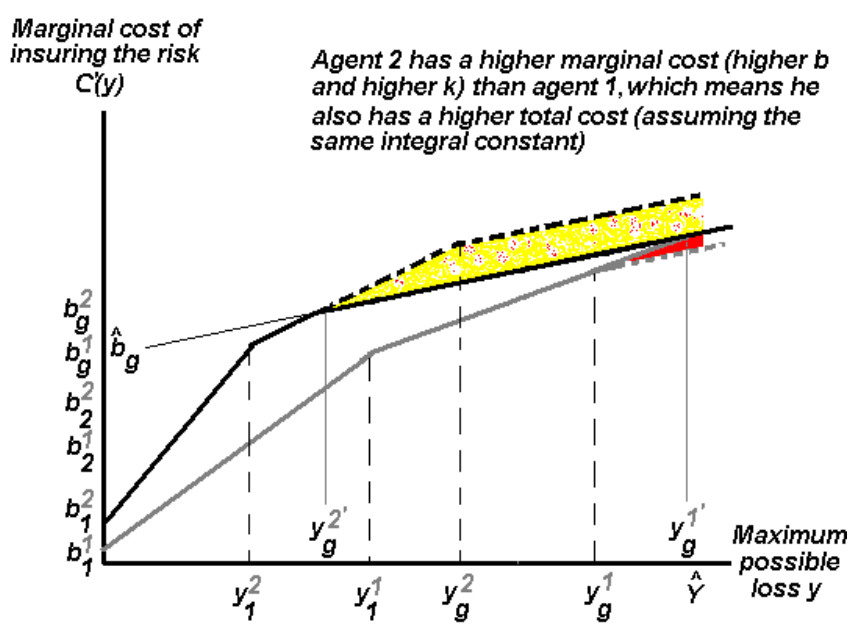

Fig. 8. Government intervention by assigning the same underwriting cost to all.

high-cost agent's decrease in total cost is given by the area in yellow. Each low-cost agent's increase in total cost is given by the area in $\operatorname{red}^{6}$.

The question, from society's point of view, is whether the area in yellow (the gain) is greater than the area in red (the loss), with each area weighted, of course, by the proportion of each type of agents in society, $\mu_{\theta}$. Surely, total welfare cannot increase given that the government's underwriting ability is a weighted function of its ability when faced with each agent separately.

\footnotetext{
${ }^{6}$ Note that we do not let the government's ability to raise money be a function of the agent type (we therefore assume that the government's financing, risk-bearing and taxing abilities are independent of risk type).
} 
We can combine the two types of intervention (same attachment point, same marginal cost function) and examine how that affects the agents' choice of insurance contracts. The problem then becomes

$$
\operatorname{Min}_{y_{1}^{\theta}} \int_{0}^{y_{1}^{\theta}}\left[b_{1}^{\theta}+k_{1}^{\theta} y\right] \mathrm{d} y+\int_{y_{1}^{\theta}}^{\hat{y}_{2}}\left[b_{2}^{\theta}+k_{2}^{\theta} y\right] \mathrm{d} y+\int_{\hat{y}_{2}}^{\hat{Y}}\left[\hat{b}_{\mathrm{g}}+k_{\mathrm{g}} y\right] \mathrm{d} y,
$$

where $\hat{b}_{\mathrm{g}}$ is defined as before as $\hat{b}_{\mathrm{g}}=\sum_{\theta} \mu_{\theta} b_{\mathrm{g}}^{\theta}$.

Our presumption is that there will be a loss of welfare for society as a whole in the event that all risk types share the same pooled fixed cost of underwriting because the government does not obey vertical equity precepts. In other words, not treating different risk types differently leads to a welfare loss. To see why, note that the gain for the high-marginalcost agents (i.e. $\theta=2$ ) is given by the difference in the area under the curves from point $y_{\mathrm{g}}^{2^{\prime}}$ until the maximum possible loss $\hat{Y}$. In our case, with one insurer, one reinsurer and one government, the gain is given by

$$
\begin{aligned}
\text { Gain } & =\int_{y_{\mathrm{g}}^{\prime}}^{y_{\mathrm{g}}^{2}}\left[b_{2}^{2}+k_{2}^{2} y\right] \mathrm{d} y+\int_{y_{\mathrm{g}}^{2}}^{\hat{Y}}\left[b_{\mathrm{g}}^{2}+k_{\mathrm{g}} y\right] \mathrm{d} y \\
& -\int_{y_{\mathrm{g}}^{2^{\prime}}}^{\hat{Y}}\left[\hat{b}_{\mathrm{g}}+k_{\mathrm{g}} y\right] \mathrm{d} y .
\end{aligned}
$$

In the case of the low-marginal-cost agent (i.e. $\theta=1$ ), his loss is given by the difference in the area under the curves from point $y_{\mathrm{g}}^{1}$ until the maximum possible loss $\hat{Y}$. With one insurer, one reinsurer and one government, the loss is given by

$$
\begin{aligned}
\text { Loss } & =\int_{y_{\mathrm{g}}^{1}}^{y_{\mathrm{g}}^{1^{\prime}}}\left[b_{2}^{1}+k_{2}^{1} y\right] \mathrm{d} y+\int_{y_{\mathrm{g}}^{1^{\prime}}}^{\hat{Y}}\left[\hat{b}_{\mathrm{g}}+k_{\mathrm{g}} y\right] \mathrm{d} y \\
& -\int_{y_{\mathrm{g}}^{2}}^{\hat{Y}}\left[b_{\mathrm{g}}^{1}+k_{\mathrm{g}} y\right] \mathrm{d} y .
\end{aligned}
$$

Given the measure $\mu_{1}$ of agents that lose and measure $\mu_{2}=$ $1-\mu_{1}$ of agents that gain, the question then becomes whether $\left(1-\mu_{1}\right)$ Gain is greater or smaller than $\mu_{1}$ Loss. We can rewrite Gain and Loss as

$$
\begin{aligned}
\text { Gain } & =b_{2}^{2}\left(y_{\mathrm{g}}^{2}-y_{\mathrm{g}}^{2^{\prime}}\right)+b_{\mathrm{g}}^{2}\left(\hat{Y}-y_{\mathrm{g}}^{2}\right)-\hat{b}_{\mathrm{g}}\left(\hat{Y}-y_{\mathrm{g}}^{2^{\prime}}\right) \\
& +\int_{y_{\mathrm{g}}^{2^{\prime}}}^{y_{\mathrm{g}}^{2}}\left(k_{2}^{2}-k_{\mathrm{g}}\right) y d y
\end{aligned}
$$

$$
\begin{aligned}
\text { Loss } & =b_{2}^{1}\left(y_{\mathrm{g}}^{1^{\prime}}-y_{\mathrm{g}}^{1}\right)+\hat{b}_{\mathrm{g}}\left(\hat{Y}-y_{\mathrm{g}}^{1^{\prime}}\right)-b_{\mathrm{g}}^{1}\left(\hat{Y}-y_{\mathrm{g}}^{1}\right) \\
& +\int_{y_{\mathrm{g}}^{1}}^{y_{\mathrm{g}}^{1^{\prime}}}\left(k_{2}^{1}-k_{\mathrm{g}}\right) y d y .
\end{aligned}
$$

We want to know if the gain outweighs the loss (i.e. what is the sign of $\left(1-\mu_{1}\right)$ Gain $-\mu_{1}$ Loss?). The function $\left(1-\mu_{1}\right)$ Gain $-\mu_{1}$ Loss is quadratic in $\mu_{1}$. We can therefore only examine the second-order condition to see if that function has a maximum or a minimum. Since by assumption we have $b_{\mathrm{g}}^{1}<b_{\mathrm{g}}^{2}, y_{\mathrm{g}}^{2^{\prime}}<\hat{Y}$ and $y_{\mathrm{g}}^{1^{\prime}}<\hat{Y}$, we can easily show that

$$
\begin{aligned}
& \frac{\partial^{2}\left[\left(1-\mu_{1}\right) \text { Gain }-\mu_{1} \text { Loss }\right]}{\left(\partial \mu_{1}\right)^{2}}=2\left(b_{\mathrm{g}}^{1}-b_{\mathrm{g}}^{2}\right)\left[\left(y_{\mathrm{g}}^{2^{\prime}}-\hat{Y}\right)\right. \\
& \left.+\left(y_{\mathrm{g}}^{1^{\prime}}-\hat{Y}\right)\right]>0,
\end{aligned}
$$

which means that we have a minimum at $\left.\left.\mu_{1}^{*} \in\right] 0,1\right]$. Consequently, there is no possible welfare gain in the government treating all risks the same way in this economy, even if the costs of underwriting is divided across all agent types.

\subsection{Public policy implications when agents have heterogeneous maximum possible losses}

Risks and agents do not need to differ only with respect to their cost functions. They can also differ with respect to their maximum possible loss. Imagine two types of catastrophic risks, one with maximum possible loss $\hat{Y}_{1}$ and the other with maximum possible loss $\hat{Y}_{2}>\hat{Y}_{1}$. Figure 9 illustrates the situation.

What would that entail in terms of government intervention? As we see, for the type of risk where the maximum possible loss is smaller, government does not appear to have a role at all since the private market is sufficiently efficient to offer the insurance product at the lowest possible cost. For the risk that has the higher maximum possible loss, the government-sponsored insurance entity has a role to play in limiting the cost of insurance to society (note again that the expected loss is independent of government intervention). This raises the interesting puzzle that if two risks (or agents or entities) have the same expected loss and the same linear marginal cost function of identifying and bearing risk, then government intervention would be warranted in the case of the risk that has the highest possible loss, but not in the case of the risk that has the lowest. 


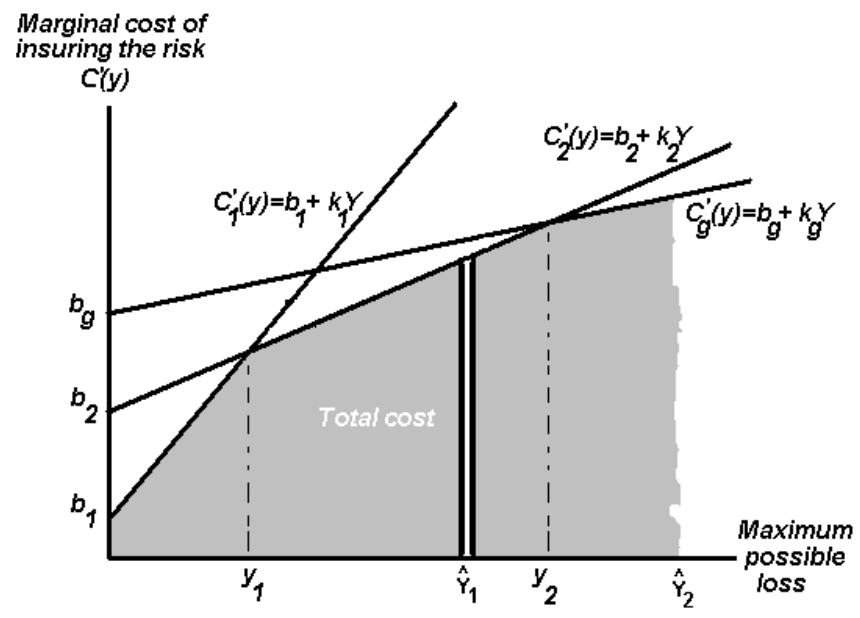

Fig. 9. Government intervention when risks have different maximum possible losses.

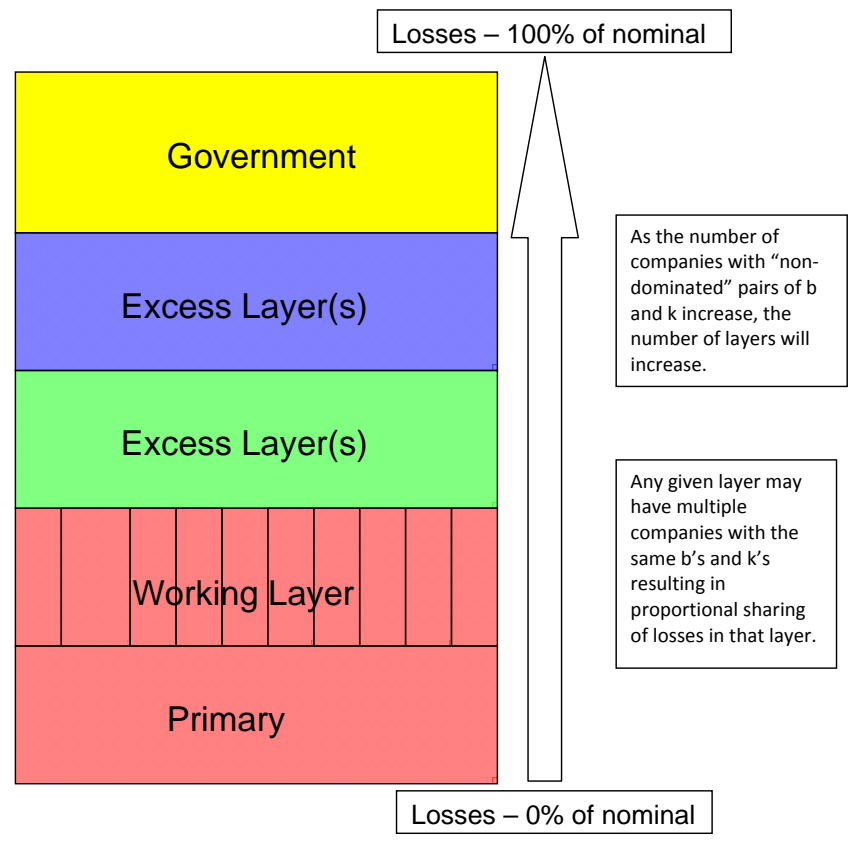

Fig. 10. Insurance programme prospective of risk sharing.

\section{Conclusions}

The financing of natural hazards and other catastrophic events is increasingly becoming a public policy issue at all government levels, and for all governments on the planet. This is true whether we are discussing naturally occurring events such as wind and ice storms in Europe, hurricanes in the southeastern United States, earthquakes in China and New Zealand or tsunamis in eastern Asia, or man-made events such as oil spills, nuclear plant breaches or chemical plant spills. The growth of the exposure in hazard-prone areas increases the importance of finding the proper price for private market insurance, and the proper role for governments in making the insurance market as efficient as possible.
This paper presented a model of the cost of providing insurance coverage against catastrophic events through the insurance market that includes not only the presence of primary insurers and reinsurers, but also, and perhaps most importantly, the implicit (or explicit) presence of governments as reinsurers of last resort. Using a classic economics approach where insurance services' production factors are separated into labour (underwriting and claims adjusting costs) and capital (risk financing), we showed how reinsurance programmes should be structured for a given catastrophic risk exposure in order to minimize the cost of such natural hazards to policyholders. The cost goes beyond the simple expected loss of a catastrophic event; the question we address is rather how one should structure the insurance, reinsurance, and government guarantee to reduce the cost in excess of the expected loss.

We derive the conditions for the reinsurance market to arise and the conditions for the net benefits of governmentprovided insurance. These depend on the diversity of the private market insurance (reinsurance) providers. While we often see primary insurers taking lower levels of insurance and reinsuring larger potential losses, the role of governmentprovided insurance has been much more diverse. There are examples of government-provided insurance acting as the primary insurer competing with private insurers (beach and windstorm plans in the US), reinsurers (Florida's Cat Fund, Terrorism Reinsurance in the US), and as sole providers (National Flood Insurance Program in the US) with no competition in the primary layer.

Even though attachment and detachment points are determined to minimize the cost of insurance protection, the cost of catastrophic insurance can nevertheless be extraordinarily high so that making the implicit government's guarantee explicit can reduce this cost. Such a reduction in the cost of bearing risk surely increases the policyholders' welfare. We are not, of course, suggesting that government should necessarily be intervening in all insurance markets - quite the contrary. Our thesis is that if government intervention in the insurance market is to increase society's welfare, then it would be at the highest possible levels of risk. Our thesis rests upon the assumption that it is the government that has the lowest cost of capital of any financial institution or entity in a country. But if we believe at the same time that the government's ability to underwrite risk (i.e. identify who has a low probability of loss and who has a high probability of loss) is poor, then the presence of government-sponsored entities in lower tranches of risk-bearing capacity reduces society's welfare.

The public policy implications of the impact of having different levels of government involved in the supply of insurance capital are not trivial. Public intervention will have an impact on the price of insurance and on the wellbeing of insurers, reinsurers, and policyholders. It will also have an impact on the tax base as every individual in the state 
or in the country becomes an "investor" of the governmentas-(re)insurer.

Acknowledgements. We would like to thank the Florida Catastrophic Storm Risk Management Center as well as the Social Science and Humanities Research Council of Canada for financial support. The continuing support of CIRANO is also gratefully acknowledged.

Edited by: F. Guzzetti

Reviewed by: R. Zoboli and one anonymous referee

\section{References}

AIR Worldwide: The Coastline at Risk: 2008 Update to the Estimated Insured Value of US Coastal Properties, Boston, Massachusetts, available at: http://www.air-worldwide.com/_public/ images/pdf/AIR2008_Coastline_at_Risk.pdf, 2008.

Albertini, L. and Barrieu, P.: The Handbook of Insurance-Linked Securities, John Wiley \& Sons, New York, 398 pp., 2009.

Berger, L. A., Cummins, J. D., and Tennyson, S.: Reinsurance and the Liability Crisis, J. Risk Uncertainty, 5, 253-272, doi:10.1007/BF00057882, 1992.

Borch, K.: Equilibrium in a Reinsurance Market, Econometrica, 30, 424-444, 1962.

Borst, D., Jung, D., Murshed, S. M., and Werner, U.: Development of a methodology to assess man-made risks in Germany, Nat. Hazards Earth Syst. Sci., 6, 779-802, doi:10.5194/nhess-6-7792006, 2006.

Boyer, M. M. and Dupont-Courtade, T.: The Market for Reinsurance, Mimeo HEC Montréal and Cirano, Scientific Series, Working Paper 2013-s06, 2013.

Cole, C. R., MacPherson, D. A., Maroney, P. F., McCullough, K. A., Newman, J. W.,, and Nyce, C.: The Use of Post-Loss Financing of Catastrophic Risk, Risk Management and Insurance Review, 14, 265-298, 2011.

Cummins, J. D. and Trainar, P.: Securitization, Insurance, and Reinsurance, J. Risk Insur., 76, 463-492, doi:10.1111/j.15396975.2009.01319.x, 2009.

Cummins, J. D., Doherty, N. A., and Lo, A.: Can insurers pay for the "big one"? Measuring the capacity of the insurance market to respond to catastrophic losses, J. Bank. Financ., 26, 557-583, doi:10.1016/S0378-4266(01)00234-5, 2002.

de Lourdes Centeno, M. and Simoes, O.: Optimal reinsurance, Revista de la Real Academia de Ciencias Exactas, Fisicas y Naturales: Serie A-Matematicas, 103, 387-405, doi:10.1007/BF03191914, 2009.

Elsner, J., Kossin, J. P., and Jagger, T. H.: The Increasing Intensity for the Strongest Tropical Cyclones, Nature, 455, 92-95, doi:10.1038/nature07234, 2008.

Emanuel, K.: Environmental Factors Affecting Tropical Cyclone Power Dissipation, J. Climate, 20, 5497-5509, doi:10.1175/2007JCLI1571.1, 2007.

Fazzari, S. M., Hubbard, R. G., and Petersen, B. C.:Financing Constraints and Corporate Investment, Brookings Papers in Economics, 1, 141-195, 1988.

Froot, K. A. and O'Connell, P. G. J.: On the pricing of intermediated risks: Theory and application to catastrophe reinsurance, J. Bank. Financ., 32, 69-85, doi:10.1016/j.jbankfin.2007.09.008, 2008.
Garven, J. R. and Lamm-Tennant, J.: Optimality of a Stop-Loss Reinsurance in Layers, Insurance and Risk Management, 7, $217-$ 237, 2003.

Hartwig, R. and Wilkerson, R.: Residual Market Property Plans: From Markets of Last Resort to Markets of First Choice, Insurance Information Institute, 2007, 2010, 2012.

Hurlimann, W.: Optimality of a Stop-Loss Reinsurance in Layers, ASTIN Colloquium International Actuarial Association - Brussels, Belgium, 2003.

Ibragimov, R. and Walden, J.: The Limits of Diversification When Losses May Be Large, J. Bank. Financ., 31, 2551-2569, doi:10.1016/j.jbankfin.2006.11.014, 2007.

Ibragimov, R., Jaffee, D., and Walden, J.: Nondiversification Traps in Catastrophe Insurance Markets, Rev. Financ. Stud., 22, 959993, 2009.

Jean-Baptiste, E. L. and Santomero, A. M.: The Design of Private Reinsurance Contracts, J. Financ. Intermed., 9, 274-297, doi:10.1006/jfin.2000.0291, 2000.

Kessler, D.: Insurance market mechanisms and government interventions", J. Bank. Financ., 32, 4-14, 2008.

Kleffner, A. E. and Doherty, N. A.: Costly Risk Bearing and the Supply of Catastrophic Insurance, J. Risk Insur., 63, 657-671, 1996.

Krausmann, E., Cozzani, V., Salzano, E., and Renni, E.: Industrial accidents triggered by natural hazards: an emerging risk issue, Nat. Hazards Earth Syst. Sci., 11, 921-929, doi:10.5194/nhess11-921-2011, 2011.

Kunreuther, H. and Michel-Kerjan, E.: At War with the Weather: Managing Large-Scale Risks in a New Era of Catastrophes, MIT Press, 2009.

Ladoucette, S. A. and Teugels, J. L.: Analysis of Risk Measures for Reinsurance Layers, Insurance: Mathematics and Economics, 38, 630-639, doi:10.1016/j.insmatheco.2005.12.005, 2006.

Lewis, C. M. and Murdock, K. C.: The Role of Government Contracts in Discretionary Reinsurance Markets for Natural Disasters, J. Risk Insur., 63, 567-597, 1996.

Michaelides, S. C., Savvidou, K., Orphanou, A., Nicolaides, K., and Tymvios, F.: Outcomes of the 10th EGU Plinius Conference on Mediterranean Storms (2008), Nat. Hazards Earth Syst. Sci., 11, 259-265, doi:10.5194/nhess-11-259-2011, 2011.

Nyce, C. and Maroney, P.: Are Territorial Rating Models Outdated in Residential Property Insurance Markets? Evidence from the Florida Property Insurance Market, Risk Management and Insurance Review, 14, 201-232, doi:10.1111/j.15406296.2011.01204.x, 2011.

Plattner, Th.: Modelling public risk evaluation of natural hazards: a conceptual approach, Nat. Hazards Earth Syst. Sci., 5, 357-366, doi:10.5194/nhess-5-357-2005, 2005.

Plattner, Th., Plapp, T., and Hebel, B.: Integrating public risk perception into formal natural hazard risk assessment, Nat. Hazards Earth Syst. Sci., 6, 471-483, doi:10.5194/nhess-6-471-2006, 2006.

Powell, L. S. and Sommer, D. W.: Internal Versus External Capital Markets in the Insurance Industry: The Role of Reinsurance, J. Financ. Serv. Res., 31, 173-188.2007.

Zanjani, G.: Pricing and Capital Allocation in Catastrophe Insurance, J. Financ. Econ., 65, 283-305, doi:10.1016/S0304405X(02)00141-1, 2002. 